\title{
Avaliação do perfil dos profissionais da área de Ortodontia quanto às condutas legais
}

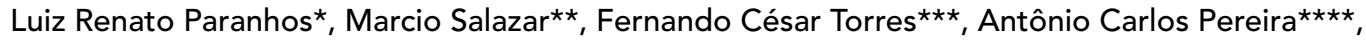 \\ Rhonan Ferreira da Silva ${ }^{\star \star \star \star \star}$, Adilson Luiz Ramos ${ }^{\star \star \star \star \star \star}$
}

\section{Resumo}

Objetivo: avaliar as condutas legais e o comportamento na relação profissional/paciente utilizadas pelos cirurgiões-dentistas atuantes na área de Ortodontia. Métodos: a população objeto do presente estudo foi constituída de 525 profissionais com cadastro na Editora Dental Press (Maringá/PR). A pesquisa foi realizada por meio de um questionário contendo 17 perguntas dirigidas a esses profissionais. Resultados e Conclusões: a maioria da população consultada é especialista em Ortodontia; 75\% dos profissionais utilizam algum tipo de contrato no consultório e/ou clínica; 73,7\% dos profissionais solicitam periodicamente radiografias de controle; grande parte dos profissionais $(58,9 \%)$ arquiva a documentação do paciente por toda a vida. Os profissionais consultados apresentam um bom conhecimento do Código de Ética Odontológica, principalmente do Capítulo XIV - da Comunicação.

Palavras-chave: Exercício profissional. Responsabilidade legal. Ortodontia. Normas jurídicas.

\section{INTRODUÇÃO}

Após a promulgação da Lei 8.078/90 (Código de Defesa do Consumidor), os pacientes passaram a reivindicar direitos na justiça, fazendo com que o cirurgião-dentista (CD) passasse a se resguardar cada vez mais quanto a eventuais processos. Então, para minimizar esse problema jurídico, torna-se necessário elaborar e manter um prontuário odontológico

Como citar este artigo: Paranhos LR, Salazar M, Torres FC, Pereira AC, Silva $\mathrm{RF}$, Ramos AL. Avaliação do perfil dos profissionais da área de Ortodontia quanto às condutas legais. Dental Press J Orthod. 2011 Sept-Oct; 16(5):127-34. completo, que contenha todos os documentos e informações do paciente.

Esses documentos são um conjunto de declarações firmadas pelo profissional, no decorrer do tratamento, que servem como prova, podendo ser utilizados com finalidade jurídica, pericial ${ }^{2,3}$ e administrativa; sendo compostos de anamnese, contrato de prestação de serviços odontológicos, consentimento esclarecido, evolução clínica do

* Doutor em Biologia Buco-Dental - FOP/UNICAMP/Piracicaba. Professor Titular do Programa de Pós-graduação em Odontologia, área de concentração Ortodontia, da UMESP/São Bernardo do Campo.

** Especialista em Ortodontia - UEM/Maringá. Doutorando em Ortodontia - UNESP/Araçatuba.

*** Doutor em Ortodontia - FOB/USP/Bauru. Professor Titular do Programa de Pós-Graduação em Odontologia, área de concentração - Ortodontia da UMESP/São Bernardo do Campo.

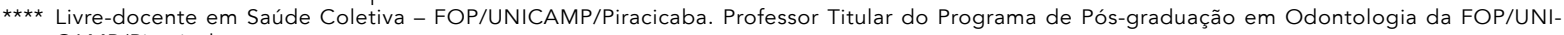
CAMP/Piracicaba.

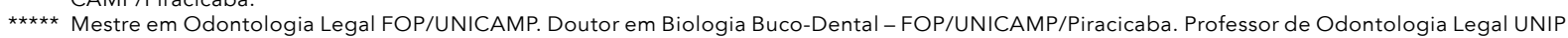
(GO). Perito Criminal Oficial da Polícia Técnico-Científica (GO).

$\star \star \star \star \star \star$ Doutor em Ortodontia e Ortopedia Facial - UNESP/Araraquara. Coordenador do Programa de Pós-graduação, Mestrado em Odontologia, da UEM/Maringá. 
tratamento, bem como as cópias de receitas, atestados e cartas de encaminhamento ${ }^{4}$.

O Contrato de prestação de serviços odontológicos e o consentimento esclarecido devem abranger todas as informações necessárias sobre a ortodontia, seus riscos e benefícios, atendimento, diagnóstico, prognóstico e plano de tratamento, bem como a estimativa de custos e de tempo de tratamento, além das informações pertinentes aos cuidados com os aparelhos utilizados e com o pós-tratamento ortodôntico ${ }^{4}$.

O contrato manifesta as condições e limitações do ortodontista como reabilitador, junto com o aceite e entendimento do paciente. Trata-se de um acordo entre duas ou mais pessoas, sobre determinado objeto lícito e possível, que visa adquirir, resguardar, notificar ou extinguir direitos ${ }^{5,6}$.

O aumento dos processos judiciais, geralmente decorre da falta de informação ao paciente, tornando-o litigioso. Por isso, faz-se necessário deixar claro quais são os objetivos almejados com o final do tratamento, quais os benefícios funcionais e qual a melhora que o tratamento proporcionará para a estética dental e facial.

Desta forma, o presente trabalho teve como objetivo avaliar o perfil dos profissionais da área de ortodontia quanto às condutas legais.

\section{REVISÃO DA LITERATURA}

Analisando a relação profissional/paciente quanto aos possíveis problemas legais originados do tratamento ortodôntico, Koubik et al. ${ }^{7}$, em 1995, concluíram que o cirurgião-dentista deve agir honestamente com seus pacientes, obtendo uma documentação clínica completa e bem detalhada, estabelecendo relações jurídicas fundamentadas em comum acordo. Isso gerará, consequentemente, um relacionamento estável entre ambas as partes, evitando futuros problemas com relação às jurisdições.

Em 2006, Melani e Silva ${ }^{6}$ aplicaram questionários dirigidos aos ortodontistas e seus respectivos pacientes com o intuito de investigar essa relação profissional/paciente, analisando-se os aspectos legais que norteiam o tratamento ortodôntico. Foi concluído que os cirurgiões-dentistas (CDs) não encaram como uma necessidade um prontuário bem elaborado, contendo informações claras e por escrito de seus pacientes, o que poderia excluí-los de processos éticos e cíveis, uma vez que esses prontuários serviriam como principal meio de defesa do ortodontista. O profissional tem se preocupado apenas com contratos que dizem respeito aos honorários e manutenções, devido à preocupação com o aspecto financeiro do tratamento.

Rodrigues et al. ${ }^{8}$ revisaram a literatura a respeito da responsabilidade civil do ortodontista, esclarecendo os direitos e os deveres no relacionamento profissional/paciente. Concluiu-se que o CD deve adotar condutas baseadas nos preceitos ético-legais, evitando um indesejado envolvimento em processos jurídicos. Portanto, o profissional deve atuar de acordo com a perícia e com os conhecimentos esperados de um CD prudente. Com relação ao paciente, o mesmo deverá ser ressarcido pelo profissional, caso haja algum dano à saúde causado àquele, como descrito no Art. 949 do Código Civil Brasileiro que prevê: "o ofensor indenizará o ofendido das despesas do tratamento e dos lucros cessantes até o fim da convalescença, além de algum outro prejuízo que o ofendido prove haver sofrido".

Garbin et al. ${ }^{9}$, em 2006, aplicaram questionários direcionados a CDs, cujas questões verificavam qual a conduta dos mesmos com relação à documentação de seus pacientes. Após a análise dos resultados, observou-se que, mesmo com riscos de sofrerem processos jurídicos, muitos profissionais são negligentes com relação à documentação de seus pacientes. Sendo assim, há uma necessidade de conscientização dos CDs com relação a esses aspectos.

Um censo estatístico foi realizado por Soares et $\mathrm{al}^{3}{ }^{3}$, em 2007, por meio de um questionário dirigido aos ortodontistas do Brasil inscritos no Conselho Federal de Odontologia (CFO), com 
o objetivo de analisar a relação paciente/profissional com o Código de Defesa do Consumidor (CDC), a natureza obrigatória dos serviços ortodônticos, e com a ciência do paciente dos riscos que o mesmo pode enfrentar durante o tratamento ortodôntico. Concluíram que o ortodontista está ciente da necessidade de colocar em prática as normas do CDC como prestador de serviço mediante seu consumidor, que no caso é o paciente. Porém, apenas uma minoria considera a atividade ortodôntica como uma obrigação de meio e mantém o paciente ciente de forma oral e registrada, dos riscos que ele está sujeito.

Kliemann e Calvielli ${ }^{10}$ analisaram o posicionamento da área jurídica sobre obrigações decorrentes da relação contratual e da correlação entre esses deveres e a atividade odontológica. Chegaram à conclusão da real importância dos cirurgiões-dentistas conhecerem tais obrigações pré-estabelecidas com seus pacientes, afinal, não basta ter conhecimento e técnica para a execução de um procedimento, mas faz-se necessário também uma conduta adequada do profissional e um prontuário bem definido, cuja finalidade é poupá-los de implicações jurídicas decorrentes do não cumprimento dos deveres contratuais.

\section{MATERIAL E MÉTODOS}

\section{Critério de escolha dos profissionais em estudo}

Foram distribuídos questionários aos cirurgiões-dentistas, atuantes na área de ortodontia, de diferentes regiões brasileiras, com cadastro na Editora Dental Press - Maringá/PR.

\section{Coleta de dados}

Realizou-se 525 questionários com 17 questões, estruturadas e abertas, direcionadas aos cirurgiões-dentistas. Os participantes receberam o questionário e uma carta solicitando a participação nesta pesquisa via e-mail. Foi-lhes assegurado a confidencialidade das informações prestadas, além do uso exclusivo para fins de pesquisa.
Os questionários não foram identificados.

O retorno para coleta dos dados foi previamente combinado com os profissionais, sendo determinado o período máximo de um mês após a entrega. Após o recebimento do questionário, os dados foram compilados e distribuídos em porcentagem por meio de gráficos que demonstram o resultado.

\section{O questionário}

O questionário levou em consideração as características referentes à formação dentro da ortodontia e os conhecimentos em odontologia legal. Em seguida, foram formuladas as seguintes questões: se utilizam algum tipo de contrato no consultório e/ou clínica e há quanto tempo; se informam o plano de tratamento e modalidade de pagamento ao paciente; se costumam oferecer mais de uma opção de tratamento e estimativa de tempo; que conduta é adotada na ausência do paciente por mais de três meses; se utilizam imagens de pacientes em folders, impressos, jornais, propaganda em TV ou em aulas; se anunciam fotos de tratamento em impressos, mostrando o início e término do tratamento e se possuem autorizações dos pacientes ou responsáveis legais por estas divulgações; se anunciam preços ou modalidades de pagamento; se já tiveram, e como foram resolvidos os problemas jurídicos; quais itens solicitam na documentação ortodôntica inicial e com qual periodicidade solicitam radiografias de controle; e, se deixam arquivadas as documentações dos pacientes e por quanto tempo.

\section{RESULTADOS E DISCUSSÃO}

A amostra constou de 525 cirurgiões-dentistas que atuam na especialidade de ortodontia e, quando questionados quanto à formação, a maioria era especialista em ortodontia, conforme mostra o Gráfico 1.

\section{Contrato de prestação de serviços odontológicos \\ Todos os cirurgiões-dentistas deveriam utili- zar em seus consultórios o contrato de prestação}




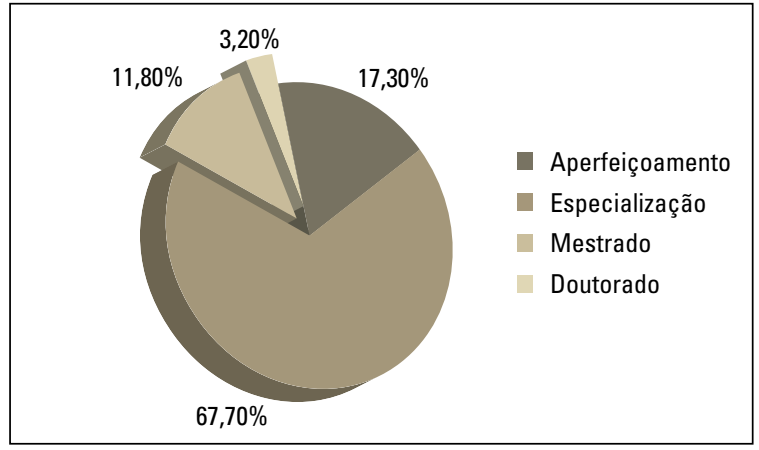

GRÁFICO 1 - Formação profissional da população do presente trabalho.

de serviços odontológicos, relevando os deveres principais de prestação de serviço odontológico, estabelecendo-se a relação jurídica ${ }^{11}$ e os deveres secundários, destinados a preparar ou assegurar a perfeita realização do dever principal.

Este contrato deve ser elaborado em linguagem simples, contendo somente termos científicos necessários, esclarecendo o que será feito dentro da especialidade, informando os riscos e benefícios do tratamento, todas as possíveis opções de tratamento dentro do limite técnico-biológico, informação de como será realizado o atendimento, além de informar os cuidados no pós-tratamento que, geralmente, são itens negligenciados ${ }^{12}$.

Também faz parte dos deveres que concernem o contrato odontológico, a biossegurança, a continuidade do tratamento, o cumprimento dos honorários, o sigilo profissional, a proteção e a vigilância, e o local onde o cirurgião-dentista fiscaliza e acompanha seu paciente, com a intenção de evidenciar a relevância do cumprimento de seus deveres ${ }^{10}$.

É notável a importância de documentar o recebimento pelo paciente das devidas instruções de higiene, quando esta não estiver junto com o contrato, prevenindo dessa forma a instalação de doença periodontal, colocando em risco o tratamento até então realizado. Também esclarecer sobre o tipo de escova que se deve usar, o tipo de fio dental, o uso de passa fio e a utilização de colutórios, a fim de eliminar e prevenir a formação do biofilme dental.
A melhor maneira dos cirurgiões-dentistas se resguardarem legalmente é por meio de uma documentação bem elaborada $4,6,7,10,12$. Garbin et al. ${ }^{9}$ (2006) observaram que a maioria dos CDs (66\%) não formaliza um termo de prestação de serviços. Melani et $\mathrm{al}^{6}{ }^{6}$, em 2006, relataram que 53\% dos pacientes afirmaram ter assinado algum tipo de documento antes de iniciarem o tratamento. Já na presente pesquisa, a maioria dos profissionais (61\%) utiliza o contrato odontológico de forma escrita e assinada, como mostra Gráfico 2.

Verificou-se nesta pesquisa que $75 \%$ dos profissionais utilizam algum tipo de contrato no consultório e/ou clínica. A maioria da amostra consultada é mais cuidadosa com relação a este procedimento, e $55 \%$ já utiliza esse tipo de procedimento de 1 a 5 anos atrás, $37 \%$ de 6 a 10 anos, e $10,30 \%$ utilizam há mais de 10 anos, como mostra no Gráfico 3.

Em 2006, Melani et al. ${ }^{6}$ observaram que poucos ortodontistas (28\%) transmitem a informação do tempo de tratamento por escrito a seus pacientes. Já neste trabalho, 78,9\% dos cirurgiões-dentistas definem o tempo de tratamento de seus pacientes e $21,1 \%$ não definem.

Com relação aos riscos do tratamento ortodôntico, Soares et al. ${ }^{3}$, em 2007, observaram que $1,23 \%$ dos ortodontistas não despertam essa relevância nos pacientes, 2,52\% anularam ou deixaram a resposta em branco, $4,29 \%$ relatam os riscos de forma escrita, $28,66 \%$ na forma oral, e $63,31 \%$ utilizam a forma oral e escrita. Além disto, os cirurgiões-dentistas passam as informações aos pacientes de forma oral em 19\%, 17\% de forma escrita, $61 \%$ de forma escrita e assinada, e 3\% utilizam outras maneiras. Rodrigues et al. ${ }^{8}$, em 2006, estão de acordo em esclarecer aos pacientes os riscos com relação ao tratamento, entre outras decorrências em função da prática da ortodontia.

Assim, orienta-se que após o diagnóstico, devem ser descritas as opções de tratamento com seu prognóstico correspondente, deixando o paciente escolher a opção de tratamento que seja mais oportuna. 


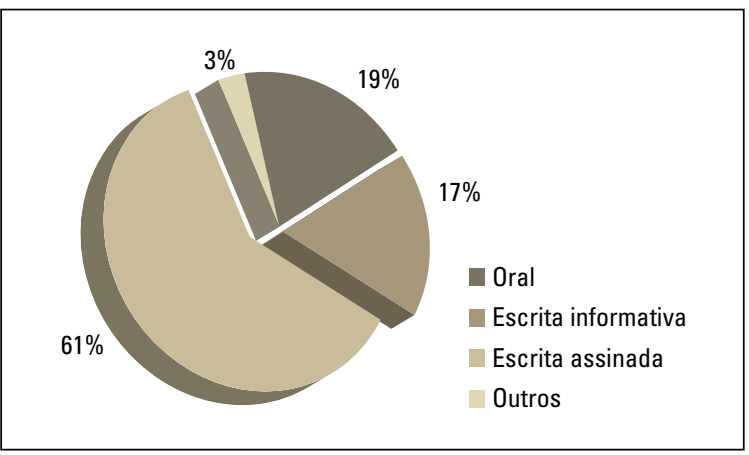

GRÁFICO 2 - Distribuição percentual quanto à forma como a maioria dos profissionais utilizam o contrato odontológico.

É preciso explicar muito bem ao paciente os limites, restrições e contraindicações de cada uma das opções, informando tudo que possa interferir direta ou indiretamente no resultado que o profissional oferece e que o paciente espera ${ }^{11,12,13}$.

Salienta-se, portanto, a necessidade de oferecer mais de uma forma de tratamento aos pacientes $^{7,11,13}$. Esta condição está em concordância com os resultados encontrados, onde a maioria dos cirurgiões-dentistas $(83,4 \%)$ apresenta aos seus pacientes mais de uma opção de tratamento.

De acordo com o Código de Ética Odontológi$\mathrm{ca}^{14}$ - cap. V, seção I, Art. $7^{\circ}$ inciso IV - constitui infração ética "deixar de esclarecer adequadamente os propósitos, riscos, custos e alternativas do tratamento". No Código de Defesa do Consumidor ${ }^{1}$, Art. 31 "a oferta e apresentação de produtos ou serviços devem assegurar informações corretas, claras, precisas, ostensivas e em língua portuguesa sobre suas características, qualidades, quantidade, composição, preço, garantia, prazos de validade e origem, entre outros dados, bem como sobre os riscos que apresentem à saúde e à segurança dos consumidores".

No presente estudo constatou-se que 92,2\% da população consultada não tiveram problemas jurídicos com seus pacientes, enquanto $7,8 \%$ tiveram. Um bom relacionamento entre profissional e paciente evita que haja envolvimentos litigiosos, impedindo a ação de responsabilidade civil contra o ortodontista $4,6,7,9,10,15$. Observou-se ainda que dos cirurgiões-dentistas que se envolveram

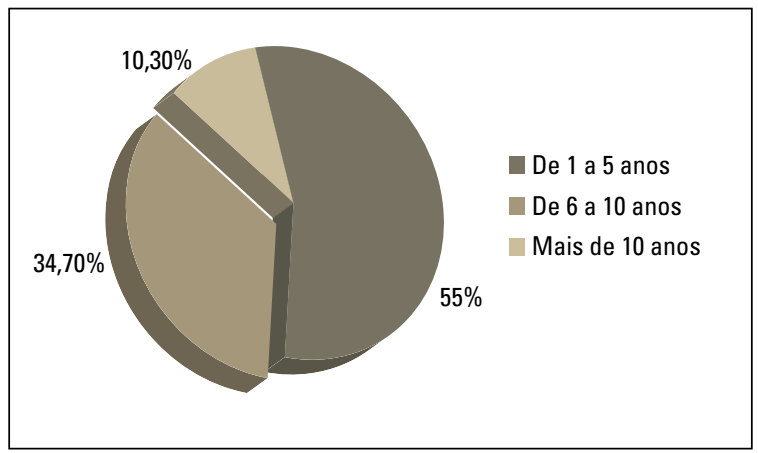

GRÁFICO 3 - Tempo de utilização do contrato na clínica odontológica da amostra consultada.

em processos, $41,5 \%$, solucionaram seus problemas via Juizado de Pequenas Causas, 29,3\% via Juizado Comum, 24,4\% via Conselho Regional de Odontologia, 2,4\% pelo PROCON, e 2,4\% não responderam à questão.

O Código de Defesa do Consumidor ${ }^{1}$, Lei no 8.078/90, em seus Arts. 2 e 3, transforma o cirurgião-dentista em fornecedor, o paciente em consumidor e a Odontologia em serviço prestado. Por isso, em todo o relacionamento $\mathrm{CD} /$ paciente, tudo deve ser muito bem esclarecido, a fim de se evitar futuros problemas jurídicos. No Art. 14, "a responsabilidade pessoal dos profissionais liberais será apurada mediante a verificação de culpa".

Consta no Código Civil Brasileiro ${ }^{16}$, Art. 186, que: "aquele que por ação ou omissão voluntária, negligenciar, violar direito e causar dano a outrem, mesmo que moral, comete ato ilícito", e este deverá reparar os danos causados a outrem (Art. 927). Ele deixa claro ainda, no seu Art. 951, que a indenização deverá ser feita por aquele que, no exercício da atividade profissional, por negligência, imprudência ou imperícia, causar a morte do paciente, agravar-lhe o mal, causar-lhe lesão ou inabilitá-lo para o trabalho.

No final do contrato de prestação de serviços odontológicos, deve-se solicitar a autorização do paciente para a execução do tratamento, para o anúncio em artigos científicos ou mesmo para anúncios publicitários, respeitando sempre o anonimato do paciente $^{4}$. Verificou-se que $26,1 \%$ dos cirurgiões-dentistas 
utilizam imagens de seus pacientes em folders, impressos, jornais, propaganda em TV ou em aulas.

A assinatura do paciente ou responsável legal nos documentos do prontuário confirma o consentimento e aprovação do procedimento ou fato citado, como determina o Código de Processo Civil ${ }^{17}$ - Seção V - Da Prova Documental - Art. 368. "As declarações constantes do documento particular, escrito e assinado, ou somente assinado, presumem-se verdadeiras em relação ao signatário".

Consultando o Código de Ética Odontológi$\mathrm{Ca}^{14}$, observa-se que constitui infração ética dentro do Capítulo XIV - Da Comunicação (seções I e III), publicar, sem autorização por escrito, elemento que identifique o paciente, expondo sua privacidade. Demonstrou-se nesta pesquisa que $43,2 \%$ possuem autorização do paciente ou responsável legal para estas divulgações, 41,7\% não possuem autorização, $15,1 \%$ não responderam. Expor ao público leigo artifícios de propaganda, com intuito de granjear clientela, especialmente a utilização dos termos "antes" e "depois", também é ilícito. Com relação a este aspecto encontrou-se que $12,8 \%$ das fotos de tratamento em impressos mostram o início e o término do tratamento, enquanto $87,2 \%$ não demonstram tal ilustração.

Em anúncio publicitário, o Código de Ética Odontológica ${ }^{14}$ diz constituir infração ética: anúncio de preços, serviços gratuitos e modalidades de pagamento que signifiquem competição desleal. Verificou-se nesta pesquisa que $0,4 \%$ divulgam preços e modalidade de pagamento, enquanto $99 \%$ não divulgam e $0,6 \%$ não responderam.

\section{Orientações legais aos ortodontistas}

$\mathrm{O}$ que fazer com a documentação ortodôntica quando do término um tratamento? Essa é uma dúvida muito comum entre os ortodontistas. Para responder esta pergunta, Garbin et al. ${ }^{13}$, em 2006, realizaram um pesquisa com 56 cirurgiões-dentistas, sendo que a grande maioria, 98\%, mantêm guardadas em arquivo, enquanto $2 \%$ as entregam aos seus pacientes sem guardar cópias em seus prontuários.

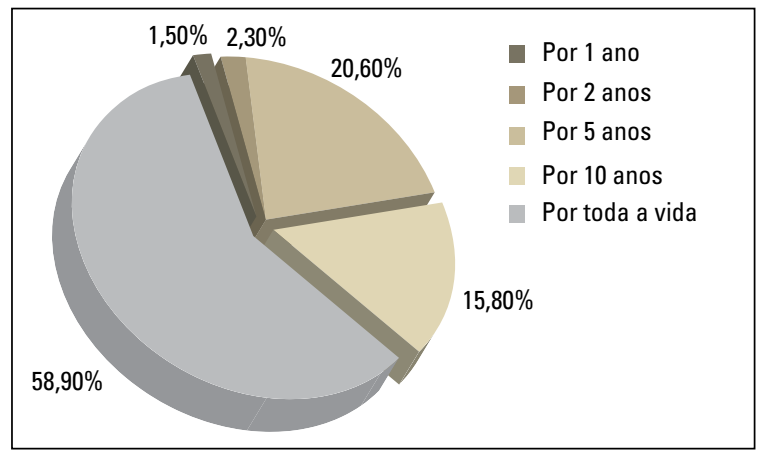

GRÁFICO 4 - Distribuição percentual quanto ao tempo de guarda da documentação ortodôntica.

Se a maioria arquiva a documentação, outra pergunta seria por quanto tempo? Esta pesquisa mostrou que $1,5 \%$ dos profissionais arquivam a documentação ortodôntica do paciente por 1 ano; 2,3\% por 2 anos; $20,6 \%$ por 5 anos; $15,8 \%$ por 10 anos; $58,9 \%$ por toda vida (Gráf. 4). Ressalta-se aqui que toda a documentação pertence ao paciente e a melhor conduta seria arquivá-la por cinco anos, para então, devolvê-la, por meio de um recibo discriminado, assinado pelo paciente ou responsável legal.

A completa documentação ortodôntica deve ser constituída de fotos intra e extra-bucais, radiografia panorâmica e telerradiografia em norma lateral, radiografias periapicais de todos os dentes e modelos de estudo. Dos questionários enviados, $0,6 \%$ responderam que solicitam apenas radiografia panorâmica, $0,9 \%$ solicitam radiografia panorâmica, telerradiografia lateral e modelo de estudo, 64\% solicitam radiografia panorâmica, telerradiografia lateral com traçado cefalométrico, fotografias intra e extra-bucais, radiografias periapicais dos incisivos e modelos de estudo, 25\% solicitam radiografia panorâmica, telerradiografia lateral com traçado cefalométrico, fotografias intra e extra-bucais e modelos de estudo, e apenas 9,5\% solicitam todos estes exames junto com radiografias periapicais da boca toda.

A solicitação de radiografias de controle (a cada seis meses) é fundamental para o diagnóstico de possiveis reabsorções durante o tratamento ortodôntico, além de manter atualizado o prontuário 
do paciente, acordando com o Código de Ética Odontológica $^{14}$. Neste trabalho, 33,5\% dos profissionais solicitam radiografias de controle de seis em seis meses, 40,2\% uma vez por ano, 19,0\% no início e no término do tratamento, $6,1 \%$ solicitam apenas no início do tratamento, e 1,2\% não responderam (Gráf. 5).

Quando o paciente se ausenta do consultório e/ou clínica, Garbin et al. ${ }^{9}$, em 2006, afirmaram que $73 \%$ dos cirurgiões-dentistas apenas telefonam para o paciente agendando um novo horário, aguardando o seu retorno. Com relação à prevalência de profissionais que enviam carta registrada ou telegrama fonado, a porcentagem foi de 16,41\%. Em nossa pesquisa, $60,6 \%$ dos ortodontistas fazem contato telefônico com seus pacientes; $2,7 \%$ contatam por carta; $28,7 \%$ por carta registrada; $8 \%$ aguardam contato do paciente. Sugere-se que, na ausência do consultório por mais de trinta dias, seja realizado contato telefônico, e se mesmo assim o paciente não comparecer, seja enviada uma carta registrada, guardando-se uma via no prontuário do paciente. Deve-se deixar claro na carta que o não comparecimento acarretará em riscos e que o não retorno caracterizará abandono do tratamento.

Foi questionado onde foi adquirida a formação ética e legal dos profissionais, e 36,3\% responderam ter sido na graduação, $45,9 \%$ na pós-graduação, 15,5\% em congressos, excelência, CRO e literatura e 2,3\% não responderam. Torna-se oportuno notar que, de acordo com a Consolidação das Normas para Procedimentos nos Conselhos de Odontologia ${ }^{18}$, os cursos de Especialização são obrigados a ministrar 30 horas de Ética e Legislação e 15 horas de Bioética. Isso sugere que muitos cursos não estão dando a devida atenção para essas

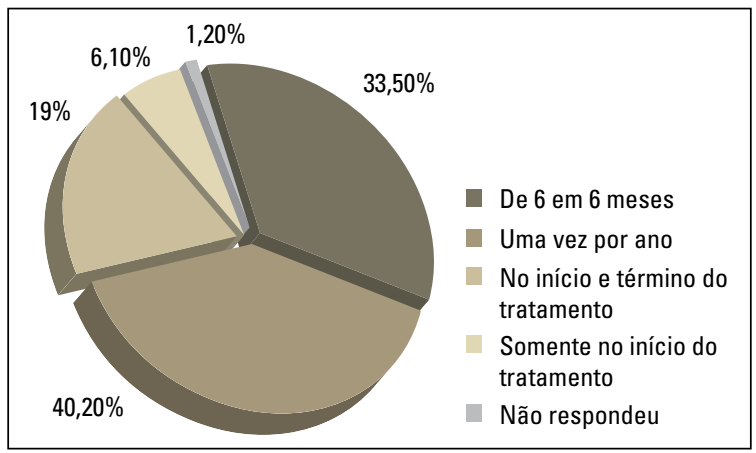

GRÁFICO 5 - Distribuição percentual da periodicidade com que radiografias de controle são tomadas durante o tratamento ortodôntico.

disciplinas, sujeitando-se a penalidades, pois desobedecem a Resolução CFO-63/2005 ${ }^{18}$. O bom relacionamento com o paciente, o preparo técnico científico e o embasamento legal do CD asseguram o excelente nível de atendimento e tratamento, além de protegê-lo contra processos ${ }^{4,15,19,20}$.

\section{CONCLUSÃO}

Baseados nos resultados, conclui-se que:

1) A maioria da população consultada é especialista em Ortodontia, e 75\% dos profissionais utilizam algum tipo de contrato no consultório e/ou clínica.

2) $92,2 \%$ da população consultada não tiveram problemas jurídicos com seus pacientes.

3) $73,7 \%$ dos profissionais solicitam radiografias de controle periodicamente.

4) $58,9 \%$ dos profissionais arquivam documentações do paciente por toda a vida.

5) Os profissionais consultados apresentam um bom conhecimento do Código de Ética Odontológica, principalmente do Capítulo XIV - Da comunicação. 


\title{
Profile evaluation of orthodontics professionals as for their legal actions
}

\begin{abstract}
Objective: to evaluate the legal actions and behavior in the doctor/patient relationship, as used by Dental Surgeons practicing Orthodontics. Methods: the population sample of the present study consisted of dental surgeons, active in the area of Orthodontics, and registered with Editora Dental Press - Maringá/PR, with a total sample size of 525 professionals. The research was conducted using a 17-question survey geared to these professionals. Results and Conclusions: the majority of participants in our study are specialized in Orthodontics; $75 \%$ of professionals use some sort of contract at the office/clinic; $73.7 \%$ of professionals periodically request maintenance $x$-rays; a large percentage of professionals (58.9\%) keep patient records on file for life. The surveyed professionals demonstrate good knowledge of the Code of Ethics in Orthodontics, especially of Chapter XIV - on Communication.
\end{abstract}

Keywords: Professional practice. Liability, legal. Orthodontics. Enacted statutes.

\section{REFERÊNCIAS}

1. Brasil. Lei no 8.078/90. Código de Defesa do Consumidor Diário Oficial da União, 11 mar 1991.

2. Silva M. Compêndio de Odontologia Legal. Rio de Janeiro: Medsi; 1997.

3. Soares ES, Carvalho AS, Barbosa JA. Relação comercial do ortodontista brasileiro com o seu paciente, natureza obrigacional dos serviços prestados e riscos do tratamento ortodôntico. Rev Dental Press Ortod Ortop Facial. 2007;12(1):94-101.

4. Paranhos LR, Salazar M, Ramos AL, Siqueira DF. Orientações legais aos cirurgiões-dentistas. Odonto. 2007;15(30):55-62.

5. Acquaviva MC. Dicionário básico de direito Acquaviva. São Paulo: Rideel; 2008.

6. Melani RFH, Silva RD. A relação profissional-paciente. $\mathrm{O}$ entendimento e implicações legais que se estabelecem durante o tratamento ortodôntico. Rev Dental Press Ortod Ortop Facial. 2006;11(6):104-13.

7. Koubik R, Feres MAL. Aspectos legais da Ortodontia. Ortodontia. 1995;28(2):64-70.

8. Rodrigues CK, Shintcousk RL, Tanaka O, França BHS Hebling E. Responsabilidade civil do ortodontista. Rev Dental Press Ortod Ortop Facial. 2006;11(2):120-7.

9. Garbin CAS, Garbin AJI, Lelis RT. Verificação das atitudes de cirurgiões-dentistas quanto à documentação de seus pacientes. Rev Assoc Paul Cir Dent. 2006;60(6):442-5.

10. Kliemann A, Calvielli ITP. Os contratos de prestação de serviços odontológicos à luz da atual teoria dos contratos. Rev Assoc Paul Cir Dent. 2007;61(2):111-4.
11. França BHS, Ribas MO, Lima AAS. Orientações legais aos ortodontistas. Rev Dental Press Ortod Ortop Facial. 2002;2(2):25-31.

12. Barros OB. Como o cirurgião-dentista deve organizar-se para evitar processos. São Paulo: Raízes; 1998.

13. França BS. Aspectos legais na Ortodontia. Rev Clín Ortod Dental Press. 2002;1(2):5-8.

14. Conselho Federal de Odontologia (BR). Código de Ética Odontológica. Rio de Janeiro; 2006. [Citado 2007 maio 7]. Disponível em: http://www.cfo.org.br.

15. Antunes FCM, Daruge E, Duz S. Reabsorções radiculares internas. Relato de um caso. Aspectos ortodônticos, clínicos e ético-legais. JBO: J Bras Ortodon Ortop Maxilar. 1998;3(13):48-59.

16. Brasil. Novo Código Civil: Lei no 10.406/2002. Diário Oficial da União, 10 jan 2002.

17. Brasil. Lei $n^{\circ} 869$ de 11 de janeiro de 1973. Institui o Código de Processo Civil Brasileiro. Brasília (DF); 1973.

18. Conselho Federal de Odontologia (BR). Consolidação das Normas para Procedimentos nos Conselhos de Odontologia. Rio de Janeiro; 2005. [Citado 2007 maio 7]. Disponível em: http://www.cfo.org.br.

19. Rosa FB. Dentista x paciente ortodôntico: levantamento de problemas jurídicos nas últimas três décadas. JBO: J Bras Ortodon Ortop Maxilar. 1998;3(13):60-76.

20. Junqueira CL, Ramos DLP, Rode SM. Considerações sobre o mercado de trabalho em Odontologia. Rev Paul Odontol. $2005 ; 26(4): 24-7$ 